\title{
AVALIAÇÃo DE MÉTOdOS DE DETERMINAÇÃo DE ÁGUA DISPONÍVEL E MANEJO DA IRRIGAÇÃO EM TERRA ROXA SOB CULTIVO DE ALGODOEIRO HERBÁCEO ${ }^{1}$
}

\author{
Carlos Cleide de Souza², Francisco Assis de Oliveira ${ }^{3}$, Ivandro de França da Silva $^{3}$ \& \\ Malaquias da Silva Amorim Neto ${ }^{4}$
}

RESUMO

\begin{abstract}
Desenvolveu-se o presente trabalho em casa de vegetação do DSER/CCA/UFPB, município de Areia, PB, objetivando-se a avaliação de dois métodos de determinação da faixa de água disponível no solo (AD), sendo um direto (MD) e outro de laboratório (ML) e o efeito da utilização de três níveis de $\mathrm{AD}$, a 10, 25 e 40\%, como indicativo para o manejo da irrigação na cultura do algodoeiro herbáceo (Gossypium hirsutum L. r. latifolium Hutch). O delineamento experimental adotado foi o de blocos ao acaso, com distribuição em esquema fatorial $2 \times 3$, com três repetições. Conforme a análise de variância, a faixa de água disponível no solo, para a cultura do algodoeiro, encontrada através da utilização do $\mathrm{MD}$, supera significativamente $(\mathrm{p} \leq 0,01)$ a obtida pelo ML. O manejo das irrigações do algodoeiro com base em $40 \%$ da $\mathrm{AD}$, determinado pelo $\mathrm{MD}$, proporciona os maiores resultados de evapotranspiração, de área foliar e acumulação de fitomassa na parte aérea da cultura. Observou-se, ainda, interação métodos x níveis de $\mathrm{AD}$, para todas as variáveis estudadas.
\end{abstract}

Palavras-chave: Gossypium hirsutum, irrigação, rendimento

\section{EVALUATION OF METHODS OF AVAILABLE WATER DETERMINATION AND IRRIGATION MANAGEMENT IN “TERRA ROXA" UNDER COTTON CROP}

\begin{abstract}
This study was conducted in greenhouse conditions at the DSER/CCA/UFPB, located in Areia, PB, Brazil. The main objective was to evaluate two methods of determination of available soil water, a direct method (DM) and a laboratory method (LM), and the effect of three levels of available water, 10,25 and $40 \%$ as indicative of irrigation management in cotton crop (Gossypium hirsutum L. $\mathrm{r}$. latifolium Hutch). A completely randomized block was utilized in a $2 \times 3$ factorial scheme, with three replications. The variance analysis showed that the values of the available soil water using the direct method were significantly $(\mathrm{p} \leq 0.01)$ higher than the laboratory method. The management of irrigation in the cotton crop using $40 \%$ of available water by DM, showed better results of evapotranspiration, leaf area and above ground biomass. Interaction of methods versus levels of available water for all variables studied was also found.
\end{abstract}

Key words: Gossypium hirsutum, irrigation, yield

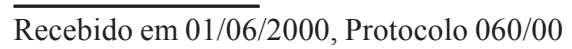

${ }^{1}$ Parte da Dissertação apresentada pelo primeiro autor ao Curso de Pós-Graduação em Manejo de Solo e Água-CCA/UFPB, Areia, PB

${ }^{2}$ Agrônomo, MSc, Bolsista/DCR-CNPq. Centro de Ciências Agrárias, CEP 58397 - 000, Areia, PB. Fone: (0xx83) 322 2457 , Fax: (0xx83) 362 2259. E-mail: oliveira@cca.ufpb.br

${ }^{3}$ Professores do DSER/CCA/UFPB. Centro de Ciências Agrárias, Bolsista do CNPq. CEP 58397 - 000 , Areia, PB. Fone: (0xx83) 322 2457, Fax: (0xx83) 362 2259. E-mail: oliveira@cca.ufpb.br

${ }^{4}$ Pesquisador, Dr. Embrapa-Algodão. CP 174, CEP 58102 - 000, Campina Grande, PB. Fone: (0xx83) 3413608 , Fax: (0xx83)341 7751. E-mail: amorim@cnpa.embrapa.br 


\section{INTRODUÇÃO}

A maioria dos trabalhos realizados com o objetivo de se estudar o manejo de água no solo considera, como água disponível às plantas, aquela retida entre as tensões equivalentes à capacidade de campo e ao ponto de murchamento permanente, ambos determinados em laboratório, conforme Richards (1947). Desta forma, considera-se como indicativo do ponto de murcha permanente o teor de água retida no solo sob tensão de $1,500 \mathrm{MPa}$ e, como da capacidade de campo, o retido a $0,033 \mathrm{MPa}$ para solos argilosos e $0,010 \mathrm{MPa}$ para arenosos, independentemente do vegetal cultivado; entretanto, quando se objetiva o estudo do comportamento da água no solo, com vistas ao manejo adequado das irrigações, deve-se levar em consideração a metodologia utilizada na determinação da capacidade de campo e do ponto de murchamento permanente.

No caso da capacidade de campo, diferenças têm sido observadas entre os diversos métodos, quando comparados com o método direto no campo, considerado o mais preciso, conforme Reichardt (1988) que, inclusive, chama a atenção para a impressão errônea de que a capacidade de campo é uma característica intrínseca do solo e independente do método empregado em sua determinação. Para o autor, o método da panela de pressão, descrito por Richards (1947) apesar de fornecer dados práticos aceitáveis, carece de respaldo teórico.

A respeito das metodologias empregadas na sua estimativa e de acordo com Marshall (1959) citado por Souza \& Reichardt (1996) não existe método de medida em laboratório que possa ser, no campo, um real substituto da capacidade de campo, devido a fatores como as características do perfil e condições iniciais de umidade do solo.

Da mesma forma, acredita-se, acontece com as metodologias aplicadas na determinação do ponto de murchamento permanente, uma vez que a capacidade de retenção de água dos solos varia principalmente com a classe textural; inclusive, determinadas plantas podem absorver água sob tensões baixas no solo. O ponto de murcha permanente é tido, normalmente, como característica estática, ao contrário da capacidade de campo que, segundo trabalhos recentes, é considerada dinâmica (Souza \& Reichardt, 1996).

O algodoeiro, conforme a pesquisa tem evidenciado, é uma planta tolerante a baixos conteúdos de água nos solos, diferentemente de culturas como o girassol e o feijão, comumente usadas como plantas-teste na determinação do ponto de murcha permanente, através do método fisiológico direto, conforme Kiehl (1979).

Diferenças entre os valores de ponto de murchamento permanente, obtidos a partir da utilização do girassol e do feijão caupi como plantas indicadoras, são registradas por Oliveira \& Martins (1966). Os autores verificaram, ainda, que em diversos solos da região Nordeste a utilização do feijão caupi, como planta indicadora, induz à obtenção de valores de umidade inferiores aos encontrados a -1,500 MPa de potencial matricial e concluíram, desta forma, que o valor do conteúdo de água a -1,500 MPa está dentro da faixa de água disponível às plantas podendo, inclusive, na maioria dos casos, substituir o valor encontrado pelo método fisiológico.
Ao trabalharem com solos de diferentes texturas, Cirino \& Guerra (1994) encontraram diferenças significativas entre os valores de ponto de murcha permanente (\% base solo seco) obtidos pelo método fisiológico, utilizando o feijão caupi como planta indicadora, e pela curva característica de retenção de água no solo (-1,515 MPa) em que os menores valores de conteúdo de água foram obtidos pelo método fisiológico.

Com as respectivas observações, deve-se considerar que os valores referentes ao conteúdo de água no solo, em condições de ponto de murchamento permanente, para plantas tidas como resistentes a déficit de água no solo, como é o caso do algodoeiro, parecem insuficientes.

Levando-se em consideração, portanto, as prováveis variações nos conteúdos de água no solo, quando este se encontra em capacidade de campo e em ponto de murcha permanente, segundo o método de determinação, conseqüentemente a faixa de água disponível ou facilmente disponível no solo, poderá ser alterada, inclusive com reflexos nos cálculos de lâminas de água para controle das irrigações.

Referindo-se ao manejo das irrigações e à demanda hídrica do algodoeiro herbáceo, são variáveis que podem ser influenciadas tanto pelas condições climáticas como pelo estádio de desenvolvimento das plantas, tipo de solo e condições de umidade no ambiente radicular (Doorenbos \& Kassam, 1994 e Tormena et al.,1999).

A afirmação de que o algodoeiro não tolera excesso de água no solo, é ressaltada por Silva et al. (1995). Neste sentido, Grimes et al. (1978) asseguram que a produção de algodão é sensível à irrigação, podendo diminuir com falta ou excesso de água no solo.

Com este raciocínio, o trabalho foi conduzido no intuito de se estudar dois métodos de determinação e três níveis de água disponível no solo, como indicativo para a reposição da água consumida por evapotranspiração pela cultura do algodoeiro herbáceo, em casa de vegetação.

\section{MATERIAL E MÉTODOS}

O trabalho foi conduzido em casa de vegetação, pertencente ao Departamento de Solos e Engenharia Rural, do Centro de Ciências Agrárias, da Universidade Federal da Paraíba (DSER-CCA-UFPB) localizado no município de Areia, PB, no período de 15.05 a 20.09.98. O local do ensaio encontra-se a aproximadamente $2 \mathrm{~km}$ ao Norte das coordenadas $6^{\circ} 58^{\prime}$ de latitude sul, $35^{\circ} 41^{\prime}$ de longitude a oeste de Greenwich e $575 \mathrm{~m}$ de altitude. De acordo com a classificação de Köppen, o clima da região é do tipo As', que se caracteriza por ser quente e úmido, com chuvas de outono-inverno e período de estiagem de 5 a 6 meses.

Utilizou-se, como substrato, uma Terra Roxa de textura franco-argilo-arenosa. $\mathrm{O}$ solo foi coletado nos $20 \mathrm{~cm}$ superficiais do perfil, horizonte Ap, cuja análise física revelou 10, 30, 74, 204, 150, 247 e $285 \mathrm{~g} \mathrm{~kg}^{-1}$ de areia muito grossa, areia grossa, areia média, areia fina, areia muito fina, silte e argila, respectivamente; densidade do solo de 1,18 e de partículas de $2,67 \mathrm{~kg} \mathrm{dm}^{-3}$; porosidade total de $56 \%$, sendo $33 \%$ de macro e $23 \%$ de microporos. Por meio da análise química foram verificados 6,80, 6,05, 0,35 e $0,15 \mathrm{cmol}_{c} \mathrm{dm}^{-3} \mathrm{de} \mathrm{Ca}^{2+}, \mathrm{Mg}^{2+}, \mathrm{Na}^{+}$ $\mathrm{e} \mathrm{K}^{+}$, respectivamente; $\mathrm{pH} 6,3 ; 23,27 \mathrm{~g} \mathrm{dm}^{-3}$ de matéria orgânica e $2,40 \mathrm{mg} \mathrm{dm}^{-3}$ de $P$. 
Os tratamentos foram definidos por dois métodos de determinação de água disponível no solo, um de laboratório e outro direto, em casa de vegetação, e três níveis de água disponível no solo, 10, 25 e 40\%, como indicativo do manejo das irrigações, ou seja, quando o fator de esgotamento chegava a 90, 75 e $60 \%$ da água disponível, o solo era irrigado manualmente, até atingir a capacidade de campo. O delineamento experimental adotado foi o de blocos ao acaso, distribuído em esquema fatorial 2 × 3 (métodos de determinação $\mathrm{x}$ níveis de água disponível no solo) com três repetições, perfazendo o total de 18 parcelas, representadas por vasos plásticos com capacidade para $20 \mathrm{~L}$, contendo solo seco ao ar, equivalente a $15 \mathrm{~kg}$ de solo seco em estufa.

Para se testar o efeito dos tratamentos, utilizou-se o algodoeiro herbáceo (Gossypium hirsutum L. r. latifolium Hutch) cultivar CNPA-7H. Durante a condução do experimento, tomaram-se dados de consumo de água (ETc), de expansão da área foliar (AF) e de acumulação de fitomassa na parte aérea (AFA) da cultura. A ETc foi determinada com base em pesagens diárias das parcelas, a AF segundo a metodologia de Ashley et al. (1963) utilizando-se a constante 0,77 como fator de correção e, como AFA, considerou-se o peso total da fitomassa da parte aérea das plantas, após secamento em estufa até peso constante.

\section{Determinação da água disponível nos solos}

Método de laboratório (ML): considerou-se ML para determinação da água disponível no solo, o descrito por Richards (1947) em que o ponto de murchamento permanente (Pmp) corresponde à água retida no solo a um potencial matricial de $-1,500 \mathrm{MPa}$ e à capacidade de campo $(\mathrm{Cc})$ a retida a um potencial de $-0,030 \mathrm{MPa}$.

Método direto (MD): como MD, foi considerado o procedimento em que o Pmp foi determinado com base no método fisiológico e a Cc por um método gravimétrico direto, ambos em casa de vegetação.

Pmp: levou-se em consideração, como Pmp, o conteúdo de água no solo em que a cultura não conseguia mais absorver água. Para sua determinação, considerou-se a metodologia descrita por Kiehl (1979) porém sem a necessidade de utilização de selamento superficial da superfície dos solos nem, tampouco, de câmara úmida, utilizando-se o próprio algodoeiro herbáceo (cv. CNPA-7H) como planta-teste.

A partir de 21 vasos contendo o equivalente a $3 \mathrm{~kg}$ de solo seco na estufa e adequadamente úmido, 10 sementes do algodoeiro foram semeadas; após a emergência das plântulas, duas em cada vaso, foram irrigadas regularmente; a partir dos 20 dias após a emergência, foi estabelecido o estresse hídrico com a supressão das irrigações, até que as plantas atingissem o Pmp.

O monitoramento da umidade do solo foi viabilizado através de amostragens, isto é, a medida em que as plantas apresentavam sintomas severos de murchamento, coletava-se uma amostra do solo para a determinação do teor de umidade; em seguida, o solo dos vasos era umedecido para que as plantas voltassem ou não à turgescência, num período nunca inferior a $24 \mathrm{~h}$ e, quando atingiam a turgescência, novas tentativas eram feitas em novos vasos e plantas, a cada $2-3$ dias, até que todas as plantas senescessem indicando, assim, o real Pmp.
Cc: foi adotado, como Cc, o conteúdo de água retida pelo solo após sofrer saturação e conseqüente ação da gravidade, até o cessamento da drenagem.

O método gravimétrico direto para a determinação da Cc foi desenvolvido a partir de 4 vasos, contendo o equivalente a $3 \mathrm{~kg}$ de solo seco em estufa. Nos vasos, o solo com estrutura deformada foi umedecido até a saturação por capilaridade, através de furos no fundo dos mesmos, por um período de 12:00 h; a partir de então, foram submetidos a drenagem por um período não inferior a 20:00 h, até o total cessamento da drenagem livre, com a superfície do solo coberta para evitar a evaporação, oportunidade em que se determinou o conteúdo de água retido.

\section{RESULTADOS E DISCUSSÃO}

Observou-se variação expressiva na faixa de água disponível no solo, em função da metodologia empregada em sua determinação. Souza (1999) assegura, inclusive, que tal variação independe da textura do solo em apreço. Os resultados obtidos registram superioridade da faixa de água disponível determinada pelo método direto, aqui considerado, em função tanto do aumento do conteúdo de água do solo em Cc como da diminuição do mesmo no Pmp conforme representado na Figura 1. Deve-se referenciar, inclusive, que nos cálculos de lâmina de irrigação usam-se, em geral, as determinações de laboratório, o que, de certa forma, subestima a capacidade de retenção de água pelo solo e, assim, a quantidade de água a ser aplicada na irrigação.

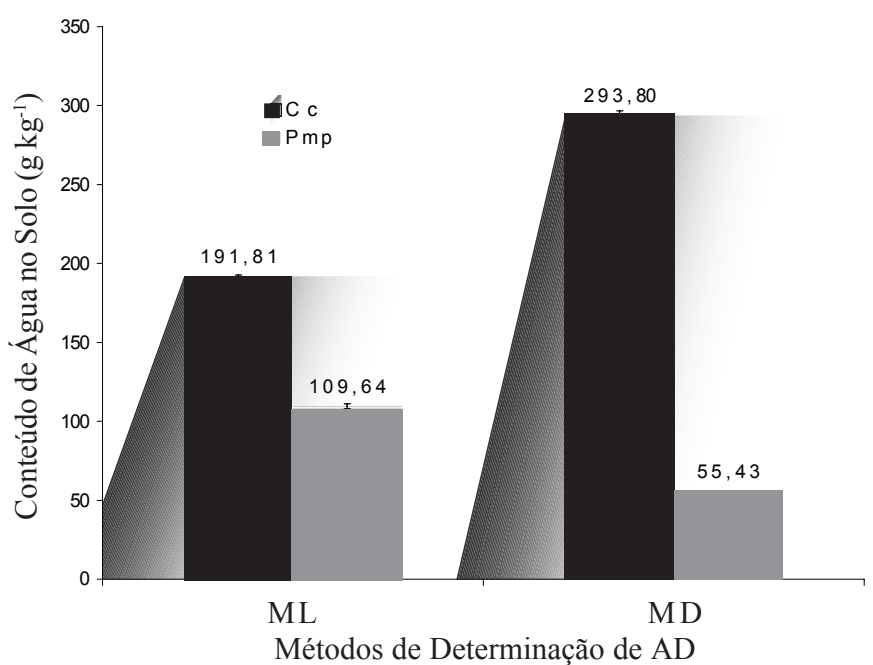

Figura 1. Conteúdo de água no solo em capacidade de campo (Cc) e em ponto de murchamento permanente (Pmp) determinado pelo método de laboratório (ML) e pelo método direto (MD). Cada ponto representa a média de 4 repetições

Com relação às diferenças entre os valores de $\mathrm{Cc}$, em que se verifica a superioridade do método direto em relação ao de laboratório, salienta-se que no método direto o solo, após umedecido, sofreu apenas o efeito da força gravitacional, força esta, certamente menos expressiva que a tensão de $0,033 \mathrm{MPa}$, preestabelecida para o método de laboratório. Quanto às diferenças encontradas entre os valores de Pmp, evidencia-se 
que, no caso do método direto, a cultura absorveu água retida no solo muito abaixo de $-1,500 \mathrm{MPa}$, potencial previamente estabelecido como indicativo do Pmp para o método de laboratório.

Ainda de acordo com os resultados apresentados na Figura 1, deduz-se que a água disponível encontrada pelo método direto $\left(238,37 \mathrm{~g} \mathrm{~kg}^{-1}\right)$ foi $190 \%$ superior à encontrada no de laboratório $\left(82,17 \mathrm{~g} \mathrm{~kg}^{-1}\right)$. Assim, entende-se que o método de determinação de água disponível influenciará diretamente nos cálculos das lâminas de irrigação. Em termos percentuais, 10,25 e $40 \%$ de água disponível, objetivo deste estudo, volumetricamente cada um desses níveis apresentará valores distintos, segundo a metodologia empregada em sua determinação influenciando, de maneira diferente, o suprimento hídrico do algodoeiro.

Neste sentido e através dos resultados da análise de variância, constatou-se efeito significativo $(p \leq 0,05)$ dos tratamentos sobre a evapotranspiração da cultura (ETc), expansão de área foliar (AF) e acumulação de fitomassa da parte aérea (AFA) revelando interação método x níveis de $\mathrm{AD}$ sobre estas variáveis.

Na Tabela 1 tem-se os resultados médios dos efeitos isolados dos tratamentos sobre a ETc, AF e AFA. Quanto aos métodos de determinação de água disponível estudados de acordo com a comparação de médias pelo teste Tukey a $5 \%$ de probabilidade, o método de laboratório superou significativamente o direto de casa de vegetação apenas na AF, podendo-se quantificar esta superioridade em 14,7\%.

Tabela 1. Médias relativas ao efeito isolado dos tratamentos sobre a evapotranspiração (ETc), área foliar (AF) e acumulação de fitomassa na parte aérea (AFA) da cultura do algodoeiro herbáceo, cv. CNPA-7H

\begin{tabular}{lccc}
\hline \multirow{2}{*}{ Tratamentos } & ETc & AF & AFA \\
\cline { 2 - 4 } & $\mathrm{mm}$ & $\mathrm{cm}^{2}$ & $\mathrm{~g}$ \\
\hline Métodos & $407 \mathrm{a}$ & $2853 \mathrm{a}$ & $30,7 \mathrm{a}$ \\
ML & $401 \mathrm{a}$ & $2487 \mathrm{~b}$ & $33,2 \mathrm{a}$ \\
MD & & & \\
Níveis de AD (\%) & $472 \mathrm{a}$ & $3225 \mathrm{a}$ & $39,9 \mathrm{a}$ \\
40 & $437 \mathrm{a}$ & $3076 \mathrm{a}$ & $34,4 \mathrm{~b}$ \\
25 & $304 \mathrm{~b}$ & $1707 \mathrm{~b}$ & $21,6 \mathrm{c}$ \\
10 & 404 & 2670 & 32,0 \\
Média & 8,0 & 9,0 & 10,0 \\
CV & 35 & 239 & 3,4 \\
DMS/método & 53 & 361 & 5,2 \\
DMS/níveis de AD & \multicolumn{2}{c}{35} \\
\hline ML: método de laboratório; MD: método direto; AD: água disponível; CV: coeficiente de variação (\%). \\
DMS: diferença mínima significativa pelo teste de Tukey a 5\% de probabilidade. Médias seguidas de \\
mesma letra não diferem pelo teste de Tukey, a 5\% de probabilidade
\end{tabular}

Para as demais variáveis não houve diferença significativa entre os métodos testados. Como no método direto, o Pmp é bem inferior ao do método de laboratório, certamente no nível de $10 \%$ de água disponível tenha concorrido para limitar o desenvolvimento da cultura, como um todo.

Ainda de conformidade com os dados apresentados na Tabela 1, observa-se que, para a ETc e a AF, não houve diferença significativa entre os níveis de 40 e $25 \%$ de água disponível; entretanto, superaram o de $10 \%$, em média, em 49,5 e $84,6 \%$, respectivamente. Quanto à $\mathrm{AFA}$, os valores decresceram com os níveis de água disponível estudados, sugerindo que o manejo das irrigações com base em $40 \%$ satisfaz melhor a exigência hídrica da cultura.

A Tabela 2 apresenta o desdobramento do efeito da interação. Ao se estudar o efeito de níveis dentro deste método (linha) observa-se que, para o método de laboratório, não houve diferença significativa entre os níveis de água disponível sobre nenhuma das varáveis avaliadas, provavelmente em função da menor amplitude verificada entre as lâminas d'água representadas por esses níveis, quando calculados por este método, demonstrando certa coerência com o demonstrado por Souza (1999). O autor, trabalhando com os mesmos tratamentos em três solos distintos, verificou que não se configura diferença significativa entre os valores de eficiência do uso da água quando se trabalha com 40, 25 e $10 \%$ de água disponível determinados pelo método de laboratório.

Quanto ao método direto e ainda com referência à Tabela 2, para as variáveis ETc e $\mathrm{AF}$ os níveis de 40 e $25 \%$ não diferiram, porém superaram o de $10 \%$, enquanto a AFA decresceu com os níveis de água disponível; provavelmente esta resposta ocorre em função da maior amplitude verificada entre os volumes de água de cada nível, quando determinados por este método, o que representa condições mais reais de disponibilidade de água no solo para a cultura.

Por outro lado, ao se estudar o efeito dos métodos dentro de cada nível (coluna) conforme a comparação das médias apresentadas na Tabela 2, observa-se que, dentre todas as variáveis, o método direto superou o de laboratório no nível de $40 \%$. Situação inversa ocorreu com o nível de $10 \%$ da água disponível, em que o método direto foi superado significativamente pelo de laboratório, em todas as variáveis. Acredita-se que, apesar do método direto exibir maior conteúdo de água no solo em condições de $\mathrm{Cc}$, este método também condiciona à obtenção de conteúdo de água muito baixo em condições de Pmp, o que se torna prejudicial para a cultura, quando se trabalha com nível inferior a $25 \%$, por afetar o estado hídrico da planta.

Tabela 2. Médias relativas ao efeito da interação método de determinação x níveis de água disponível, sobre a evapotranspiração (ETc), área foliar (AF) e acumulação de fitomassa na parte aérea (AFA) da cultura do algodoeiro herbáceo, cv. CNPA-7H

\begin{tabular}{|c|c|c|c|c|c|c|c|c|c|}
\hline \multirow{3}{*}{ Método } & \multicolumn{3}{|c|}{ ETc } & \multicolumn{3}{|c|}{$\mathrm{AF}$} & \multicolumn{3}{|c|}{ AFA } \\
\hline & $40 \%$ & $25 \%$ & $10 \%$ & $40 \%$ & $25 \%$ & $10 \%$ & $40 \%$ & $25 \%$ & $10 \%$ \\
\hline & \multicolumn{3}{|c|}{$\mathrm{mm}$} & \multicolumn{3}{|c|}{$\mathrm{cm}^{2}$} & \multicolumn{3}{|c|}{$\mathrm{g}$} \\
\hline ML & $440 \mathrm{bA}$ & $410 \mathrm{aA}$ & $372 \mathrm{aA}$ & $3013 \mathrm{bA}$ & $2976 a A$ & $2570 \mathrm{aA}$ & $34,3 \mathrm{bA}$ & $30,9 \mathrm{bA}$ & $27,0 \mathrm{aA}$ \\
\hline \multirow[t]{4}{*}{ MD } & $504 \mathrm{aA}$ & $463 \mathrm{aA}$ & $238 \mathrm{bB}$ & $3438 \mathrm{aA}$ & $3177 \mathrm{aA}$ & $8456 \mathrm{bB}$ & $45,5 \mathrm{aA}$ & $38,0 \mathrm{aB}$ & $16,2 \mathrm{bC}$ \\
\hline & \multicolumn{3}{|l|}{ CV: 8} & \multicolumn{3}{|l|}{ CV: 9} & \multicolumn{3}{|l|}{ CV: 10} \\
\hline & \multicolumn{3}{|c|}{ DMS/coluna: 61} & \multicolumn{3}{|c|}{ DMS/coluna: 414} & \multicolumn{3}{|c|}{ DMS/coluna: 5,9 } \\
\hline & \multicolumn{3}{|c|}{ DMS/linha: 76} & \multicolumn{3}{|c|}{ DMS/linha: 510} & \multicolumn{3}{|c|}{ DMS/linha: 7,3} \\
\hline
\end{tabular}
para colunas e maiúsculas para linhas, não diferem pelo teste de Tukey, a $5 \%$ de probabilidade 
Para Moreshet et al. (1996) o estado hídrico das plantas depende do balanço entre o influxo do solo e o efluxo para a atmosfera. Segundo os autores, quando o conteúdo de água do solo é sensivelmente reduzido, há diminuição do contato com as raízes, cuja extração é mais intensa, interrompendo o fluxo, podendo ser reversível com a irrigação. Para Reddy et al. (1997) os potenciais hídricos negativos do tecido provocam reduzida expansão do tecido, taxas fotossintéticas menores e fechamento de estômatos, o que certamente ocorreu neste caso.

Em termos de interação método x níveis de água disponível, conforme desdobramento apresentado na Tabela 2, em todas as variáveis os maiores resultados foram observados em função do método direto quando se trabalhou com o nível de $40 \%$; entretanto, para ETc e AF não houve diferença entre os métodos para o nível de $25 \%$ de água disponível sugerindo, assim, que o melhor nível utilizado como indicativo para reposição da água consumida pela cultura, depende diretamente da metodologia empregada na sua determinação.

\section{CONCLUSÕES}

1. A faixa de água disponível no solo, para a cultura do algodoeiro herbáceo, depende do método de determinação da capacidade de campo e do ponto de murchamento permanente.

2. O nível de água disponível no solo mais indicado para manejo das irrigações, na cultura do algodoeiro em Terra Roxa, depende diretamente da metodologia empregada na sua determinação.

3. O manejo das irrigações do algodoeiro com base em $40 \%$ da água disponível, determinado pelo método direto, proporciona os maiores resultados de evapotranspiração, de área foliar e acumulação de fitomassa na parte aérea da cultura.

\section{REFERÊNCIAS BIBLIOGRÁFICAS}

ASHLEY, D.A.; DOSS, B.D.; VENNETT, O.L. A method of determining leaf area in cotton. Agronomy Journal, Madison, v.25, p.484 - 5, 1963.

CIRINO, C.G.; GUERRA, H.O.C. Utilização das relações energia/ umidade na caracterização físico-hídrica dos solos. Pesquisa Agropecuária Brasileira, Brasília, v.29, n.12, p.1973-8, 1994.
DOORENBOS, J.; KASSAM, A.H. Efeito da água no rendimento das culturas. Campina Grande: UFPB, 1994. 306p. il. Estudos da FAO: Irrigação e Drenagem, 33

GRIMES, D.W.; DICKENS, W.L.; YAMANDA, H. Early season water management for cotton. Agronomy Journal, Madison, v.70, n.6, p.1009-12, 1978.

KIEHL, E.S. Manual de edafologia: Relações solo - planta. São Paulo: Ceres, 1979.262p.

MORESHET, S.; FUCHS, M.; COHEN, Y.; COHEN, Y.; LANGENSIEPEN, M. Water transport characteristics of cotton as affected by drip irrigation layout. Agronomy Journal, Madison, v. 88, n.5 , p.717-22, 1996.

OLIVEIRA, L.B. de; MARTINS, A.M.C.M. Considerações sobre a umidade de 15 atmosferas e a umidade de murchamento (método fisiológico) em solos do Nordeste. Pesquisa Agropecuária Brasileira, Brasília, v.1, p.91-5, 1966.

REDDY, K.R.; HODGES, H.F.; McKINION, J.M. Crop modeling and application: A cotton example. Advances in Agronomy, New York, v.59, p.226-82, 1997.

REICHARDT, K. Capacidade de campo. Revista Brasileira Ciência do Solo, Campinas, v.12, n.3, p.211-6, 1988.

RICHARDS, L.A. Pressure-membrane apparatus, construction and use. Agronomy Engineering, Madison, n.28, p.451-4, 1947.

SILVA, M. da; CARVALHO, L.H.; CIA, E.; FUZATTO, M.G.; CHIAVEGATO, E.J.; ALLEONI, L.R. Seja o doutor do seu algodoeiro. In: POTAFOS. Arquivo do Agronômico. Piracicaba, SP, n. 8, p.1-23, 1995.

SOUZA, C.C. de. Avaliação de métodos de determinação de água disponível em diferentes solos na cultura do algodoeiro herbáceo. Areia: UFPB/CCA, 1999, 84p il. Dissertação Mestrado

SOUZA, L.D.; REICHARDT, K. Estimativas da capacidade de campo. Revista Brasileira Ciência do Solo, Campinas, v.20, n.2, p.183-9, 1996.

TORMENA, C.A.; SILVA, A.P. da; GONÇALVES, A.C.A.; FOLEGATTI, M.V. Intervalo ótimo de potencial de água no solo: um conceito para avaliação da qualidade física do solo e manejo da água na agricultura irrigada. Revista Brasileira de Engenharia Agrícola e Ambiental, Campina Grande, v.3, n.3, p.286-92, 1999. 